\title{
Monomer Deletion Process
}

National Cancer Institute

\section{Source}

National Cancer Institute. Monomer Deletion Process. NCI Thesaurus. Code C157221.

The process of removing one or more repeating units from a polymer. 